\title{
An English Psychiatrist in Ontario
}

\author{
J. L. Crammer, Emeritus Reader in Biological Psychiatry (University of London), Maudsley Hospital, London
}

After 30 years of psychiatry in England I've just had a cold plunge through Canadian psychiatry as a staffman in an Ontario general hospital. Because science is international and a good many British psychiatrists work in Canada I expected clinical practice to be the same: but psychiatry is different on the two sides of the Atlantic. Before my raw, insistent perceptions of these differences fade, as they do so quickly when one adapts to a new life, I will write some of them down. However faulty they form a rough mirror in which we can all examine our own professional faces.

I was struck the first day by the number of obese women in the streets, not just the middle-aged but the twenties and teens. Do they come to psychiatrists to help them slim, as they might in England? Is the incidence of anorexia nervosa different here? The second shock was that almost every patient I saw, whatever the presenting problem, gave a history also of excessive alcoholic drinking. Obesity and alcoholism are two scourges of the rich, and we are poorer in England. In the psychiatric hospital I discovered that excessive water drinking, and even water intoxication at times, occurred on a scale I had never before encountered or heard of, though it turns out to be well known in the chronic schizophrenics of North America. Yet we all use the same psychotropic drugs in a similar way. In Emergency, overdoses (parasuicide) seemed less severe and less common. I do not know whether these seeming differences in prevalence are documented and studied, but if not they certainly should be, not simply between London and Toronto and Montreal, but between Vancouver and Winnipeg and Ottawa and well. Differences, if they exist, should lead to understanding of the social influences determining psychological disturbances.

The psychiatrist arriving in Canada has a different workload, not only because of differences in the prevalence of different disorders, but because Canadians can express their view of what psychiatry is for in a way the British cannot. Any Canadian can seek an appointment with any psychiatrist, if he so wishes, and some come not because of illness or disability but because they are encountering some stress of everyday life and believe that talking about it with a psychiatrist will help him to handle it. One man comes because his wife has left him and he wants her back, another because an estate agent has persuaded him to buy a house he does not want, a woman because of arguments with her husband over the way to bring up the children. In Britain a patient cannot go direct to a specialist but must first go to his family doctor (GP) who decides whether the problem is for any specialist, medical or otherwise. In consequence the British psychiatrist only sees a pre-selected group of patients, screened according to the family physician's view of psychiatry, not the patient's.

There is also a difference between the Canadian and the British psychiatrist's view of his own role. Some Canadian colleagues have told me they regard psychiatry as a medical luxury, relieving some of the unhappiness in the world. Others think that psychiatry is there to help people make the best of themselves, a spiritual training which should be available to anyone who wants it. Well of course psychiatric treatment may relieve unhappiness and be a form of education, but to the majority of British psychiatrists these are peripheral aims. As a physician in psychological medicine, I want to use my medical expertise first and foremost to avert death, to cure disease, to overcome disabilities (i.e., to treat the sick), not to minister to unhappiness or encourage and educate the healthy-which I leave to other non-medical counsellors, teachers, clergy, friends. I am not interested in someone who feels depressed, until he can show that his abilities to work and play are also diminished, that his condition is to some degree a disabling one. For me the psychiatric patient is always someone with a diminished freedom, whose activities are limited (e.g. by cognitive disorder, or by anxieties or fears or compulsions), so that in the spheres of work or sex or social action the patient cannot act as he would like. It is my job to restore him if I can to full function or to find ways of minimising his disabilities by social manipulations.

Psychoanalysis has played a much smaller part in British than in North American psychiatry and this may explain the difference between the British and Canadian views on role. On this side of the Atlantic there has been more concentration on the individual's psychodynamics, ignoring his family and friends with whom he interacts and who also thereby influence outcome. On the British side there has for long been concern over the patient's emotional situations at home and at work, and a part of the patient's treatment is devoted to changing attitudes of others or to moving him into more sympathetic environments. There has been little interest in intensive psychotherapy-for which many patients as screened by GPs seem unsuited.

Under the Ontario Health Insurance Plan (OHIP) the state pays the doctor a fee for each item of service offered the patient. ${ }^{1}$ In contrast the British National Health Service (NHS) makes block payments, irrespective of the work done. Both family physician and specialist are free to undertake private practice but they also contract to work to a variable extent for the NHS, and for this the state pays. The family doctor takes named members of the local population on his list and receives an annual payment for each name, whether they consult him or not in the year. The psychiatrist agrees to give up to 10 half days per week of his time to NHS psychiatry, and receives a salary accordingly, but what he actually does in those sessions depends largely on his own decisions and the pressures of his colleagues.

These two very different systems of payment express different philosophies and limit psychiatric practice in different ways. The OHIP system respects each doctor as an 
individual, working for the individual patient in a close relationship: it is a medical system, but it encompasses individual betterment, relief of individual distress. When the patient is better he is expected to manage for himself again in the individualistic pioneering American way. So patients do not belong so closely to a single doctor, and doctors are not expected to collaborate in the individual's care-hence the fact that some Canadian GPs will go away for a time and leave the care of their patients to Emergency, and that many do not send referral letters to specialists with their patients. Hence also less interest in follow-up care when the patient has completed medical treatment, and a tendency to ignore repercussions on the family. This works least well with long-term cases, such as alcoholism or the troubles of old age, where there are large social as well as medical components, and seems to lead to a fragmentation of care.

The NHS is collaborative and not individualistic, includes social workers and community nurses as well as doctors in its scheme of care and tries to weld home and hospital treatment and the solution of social problems into one network of support, with the family physician as central coordinator. The psychiatrist has always been encouraged to meet family doctors for case discussion, expects often to treat his outpatients in conjunction throughout with their GPs, and as many as one psychiatrist in five now has regular meetings with GPs in their offices, and may conduct clinics there. Since the pay is the same whatever he does the British psychiatrist can be flexible in choosing how to work. In contrast, OHIP has a big book specifying the fee for each item of service. A procedure not in this book is not paid for. This is bound to shape Canadian practice where time is money, discouraging low fee activities or any procedures unlisted, and tending to inhibit any evolution in practice.

Canada is a society with a great respect for lawyers and for keeping the law, Britain is not. Canada has great faith in writing things down, and in scrupulously respecting the written words even if they do not quite cover the real life situation: individual common sense is not allowed to override the rule book. In psychiatry accurate information about a patient's past life and communication between the different agencies caring for him are of first importance in diagnosis and management-for his sake, for society's sake, for sensible use of financial and other resources. To quite an absurd extent the use of Form 14 blocks all this. ${ }^{2}$ The patient's privacy must be preserved, 'confidentiality' maintained to the limit even if this means he will get poor or wrong treatment. This seems to me legalism before common sense. At least since Nelson put his telescope to his blind eye and said 'I see no orders' there has been in Britain a tradition of empiricism in action, of putting common sense first.

European psychiatry as developed is city psychiatry, because city folk wanted their socially disruptive elements, psychotics, rogues, vagabonds, and criminals isolated and neutralised, and their relationship problems of marriage, parenting, and large-scale industry smoothed out. Rural folk, farmers and peasants, meet these 'problems' less acutely, sometimes perceive them differently, and inevitably because of geographical dispersion need a different kind of psychiatric service. Britain, a country one quarter the size of Ontario with a population five times greater, is virtually all city and no peasants, and European psychiatry suits it well. Canada, in contrast, is a continent of long and difficult communications with some big cities, and many small scattered rural populations for whom European psychiatry cannot be applicable, any more than it is in rural China or Peru. Experience of mental health centres in Botswana or in India may have something instructive for helping Inuit or Cree or the small communities of Northern Ontario.

China just now is undergoing a reverse influence, the arrival of European psychiatry in the big cities, and it is interesting to see how this development is shaped by public demand, by more patients, and especially many more women coming forward for treatment, and by magistrates and police seeking psychiatric aid for arsonists and sexual deviants. The state also is interested in efficacious treatment of the elite-the scientists, plant managers, economic planners, teachers and doctors and other trained personnel in such short supply on whom Chinese modernisation depend. A doctor disabled by psychological illness is a waste of society's resources, and getting him back to full work as soon as possible is very important. It shows very clearly here that psychiatry can be much more than a medical luxury or a spiritual training, and ways in which governmental and popular pressures shape psychiatric practice. The same processes are at work everywhere, though demands may be satisfied differently in different societies. What Canada and what Britain want seem to be different. The British doctor going to work in Canada must be sensitive to this difference.

\section{Footnotes}

${ }^{1}$ Note that the work of the 10 Ontario mental hospitals is outside this form of health service and governed directly by the Ministry of Health. A licence to practise in the mental hospital service is a licence only for that and does not allow participation in OHIP or in full private practice: the wider and fuller licence is now very difficult for non-Canadians to obtain. On the other hand things differ somewhat in the other Canadian provinces: one needs to find out precisely. ${ }^{2}$ Form 14 is a legal document which must be signed by every patient, and countersigned by a witness other than the doctor, authorising disclosure or transmittal to or examination by the named doctor of the clinical record previously compiled. Without this authorisation it is illegal for the hospital doctor to tell the GP what drugs a patient is having on discharge from hospital (or indeed to make any communication to the GP at all), or for a consultant to write back any opinion on an outpatient referred to the GP who has asked for one. Nor will any medical records officer release any hospital case notes to the doctor now endeavouring to treat the patient. The paranoid, the deluded, the demented, manipulators and those who make a good thing out of repeated hospital admissions are only too likely to refuse to sign.

We thank the Canadian Psychiatric Association for permission to reprint this article which first appeared in their Bulletin. 